\title{
Lamento a la muerte de Jorge Velazco
}

\author{
por \\ CONSUELO CARREDANO
}

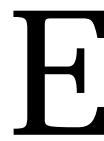

I Instituto de Investigaciones Estéticas de la unam está de luto. El martes 5 de agosto de 2003 , después de dirigir un par de memorables conciertos con la Sinfónica de M inería, orquesta que él mismo fundara en 1978, el maestro Jorge Velazco (M éxico, D.F., 1942) falleció en la ciudad de M éxico.

Al cambiar los tratados de derecho por los de armonía y orquestación, y sus papeles curiales por las hojas pautadas, Jorge Velazco dio un giro radical a su vida y abrazó a la música como una pasión sustancial. A la par de sus estudios en la Facultad de D erecho de la unam y una consecuente especialización en Londres gracias a una beca del Consejo Británico, había recibido una sólida preparación musical, sin duda iniciada desde temprana edad con buenos maestros mexicanos: Antonio G omezanda, Conrado Tovar, Rodolfo $\mathrm{H}$ alffter. Luego, en el extranjero, Velazco asistió a cursos y seminarios con figuras prominentes de la escena internacional, como Lukas Foss en Estados Unidos, Franco Ferrara en la Accademia M usicale C higiana de Roma y H erbert von Karajan en el seminario de dirección de orquesta que éste impartía en la Escuela Juilliard de Nueva York en i976, y al año siguiente, en Berlín.

Sin embargo, y aunque no hacía gala de ello, sus inicios profesionales en la música se dieron por la vía de la ejecución pianística, una actividad a la que dedicó poco tiempo pero que obtuvo un merecido reconocimiento de nuestra comunidad musical. Interpretó recitales de repertorio clásico y romántico, conciertos como solista de la O rquesta Filarmónica de la unam e hizo destacadas incursiones en la música de vanguardia al mediar los años 70, ofreció algunos estrenos absolutos y primeras audiciones en M éxico en conciertos, auspiciados entonces por foros como la C asa del Lago y la Biblioteca Benjamin Franklin.

N o obstante, su vocación se inclinó hacia la dirección de orquesta, una trayectoria por demás conocida sobre la que prevalecen encontradas opiniones y que, desde 1976, sumó sostenidas actuaciones con diversos conjuntos europeos: en Berlín, como principal director huésped de la Sinfonietta RIAS, y en 
I82

varias ocasiones, de la D eutschen Symphonie O rchester y la O rquesta Sinfónica de esa misma ciudad. Con cada una de estas orquestas grabó dos discos en Alemania. También fue invitado por la O rquesta Nacional de España en 1995 y, entre 1989 y 2002, fungió como huésped principal de la O rquesta de Cámara de Florencia. En Estados U nidos dirigió las orquestas de Atlanta, Baltimore, Brooklyn, H ouston, Louisville, M ilwaukee, Sacramento y San Antonio, entre otras, y, a lo largo de su carrera, estuvo al frente de conjuntos mexicanos como la Filarmónica de la Ciudad, la O rquesta Sinfónica N acional y las sinfónicas del Estado de M éxico y de Xalapa. Durante más de siete años fue director de la Sinfónica de M inería, cargo al que tuvo que renunciar cuando fue designado director artístico de la 0 rquesta Filarmónica de la unAm, y que volvería a asumir en ig95 hasta la fecha de su muerte.

En una forma u otra, Jorge Velazco impuso su vocación musicológica a su papel de director. Además de conocer a fondo los aspectos históricos, técnicos e interpretativos de las partituras, tomaba el cuidado de redactar las notas de sus programas: una preocupación y un ejercicio ajenos a la mayoría de los directores mexicanos, con las estimables excepciones de un par de pioneros de nuestro sinfonismo histórico, que sin duda inspiraron en buena medida la inquietud de Velazco. Esta genuina devoción hacia la musicología se revelaba en sus novedosos criterios de programación. Aun tratándose de obras del repertorio tradicional, Velazco era afecto a las interpretaciones apegadas al rigor histórico y a aventurarse a probar ediciones especiales y orquestaciones originales. En algún momento también mostró interés por el rescate de obras mexicanas de escasa o nula difusión. Bastaría mencionar un par de ejemplos: en 198I, el estreno en M éxico del Concierto para violonchelo de Ricardo Castro con la O rquesta Sinfónica de M inería y el violonchelista Carlos Prieto, una obra que había tenido una sola interpretación en París, en el remoto año de i903. Velazco consiguió una copia del manuscrito en la Colección Edwin E. Fleischer de la Free Library de Filadelfia y dirigió al propio Prieto y a la O rquesta Sinfónica de Berlín en una grabación posterior. Y, en segundo lugar, la Sinfonía de Antonio Sarrier, cuya grabación con la orquesta RiAs, en 1982, respeta, al uso de la época, la tesitura original de los cornos, y que después volvió a ejecutar en uno de los programas de la ofunAm, antes de grabarla con el mismo intérprete en Berlín.

Jorge Velazco no se limitó a empuñar la batuta de director bajo los reflectores internacionales 0 a redactar sus investigaciones en la soledad del cubículo de su Instituto, en el que trabajó durante cerca de tres décadas: "Todo el 


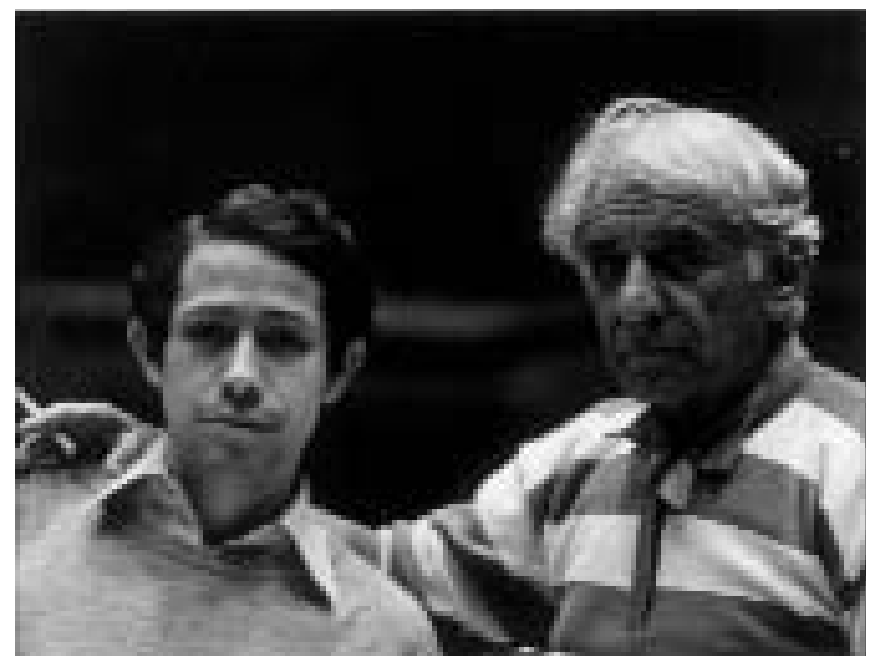

I. Jorge Velazco con Leonard Bernstein, director y compositor estadounidense. Reprografía: G erardo Vázquez M iranda, Archivo Fotográfico IIE-UNAM.

que pueda debe divulgar", escribió como una declaración de principios en el prefacio a su libro La música por dentro (M éxico, unam, 1977). Y fue ciertamente en el campo de la divulgación musical donde cosechó algunos de sus mejores frutos. D urante largos años, Velazco publicó en las páginas de Excélsior puntuales artículos en los que abordaba un sinnúmero de temas relacionados prácticamente con todas las áreas de la música y todos los periodos de su historia. Sus posturas eran abiertamente críticas hacia el muy limitado conocimiento del pasado musical mexicano. Pero también, como agudo observador del ambiente artístico de su tiempo, disparó, no sin razón en algunos casos, anatemas contra el stablishment musical, los medios masivos de comunicación, ciertos melifluos funcionarios culturales y los críticos poco preparados que escriben con vergonzante irresponsabilidad.

Como lo señala acertadamente el musicólogo Ricardo M iranda, una de sus quejas más constantes era acerca del pobre conocimiento que se tiene del acervo musical de M éxico. Convencido de la necesidad de rescatar del olvido a los músicos anteriores a las grandes figuras como Ponce, $C$ hávez o Revueltas, desde los años 70 Velazco se abocó a la tarea, entonces poco frecuente, de publi- 
I84

car breves retratos de aquellos compositores olvidados, cuando todavía era difícil encontrar documentación suficiente o grabaciones de su obra. Algunos títulos de estos rescates son elocuentes: "La obra olvidada de Campa", "La figura congelada de C arrasco", "La música perdida de M iramontes" y "La figura borrosa de Felipe Larios". El musicólogo estadounidense Robert Stevenson celebra en la labor de Velazco una genuina forma del patriotismo musical que consiste en un sano respeto por el pasado de un pueblo. Y aunque los escribie ra con un claro propósito de divulgación y pese a su brevedad, denotan juicios estéticos de gran penetración, en muchos casos, una buena dosis de ingenio y hasta un peculiar sentido del humor que refleja algunos rasgos de su controvertida personalidad. Si bien era un hombre pragmático y culto, ávido lector de buena literatura y bien educado, su carácter, como él mismo solía reconocerlo, no era fácil y podía desconcertar a más de uno.

Por lo demás, ¿qué tanto de su personalidad afloraba en su obra musicológica? Fetichista y amante de las rarezas, de los temas mágicos, mostraba una inusual predilección por los personajes históricos que, sin ser músicos, mantenían estrechos lazos con la música. Así, por ejemplo, escribió varias decenas de artículos sobre reyes melómanos, aristócratas aficionados o gobernantes compositores, además de un trabajo de mayor alcance sobre Federico II de Prusia y la música (unAM, 1986). También cabe mencionar sus escritos sobre los "científicos" de la música o figuras como el Leonardo da Vinci intérprete e inventor de instrumentos, sobre H erschell que, además de astrónomo, fue un prolífico autor de obras musicales, o bien acerca de compositores que fueron médicos, atletas, espadachines y empresarios de éxito. Asimismo, le gustaba descubrir facetas poco conocidas de músicos conocidos. Como lo señala el mismo Ricardo M iranda, "además de ser una de sus obsesiones, constituye una parte fascinante de su legado musicológico y puede ser, sin lugar a dudas, una puerta muy agradable para acercarse a la música o para despertar el interés de la gente por la música". Por fortuna, la mayoría de estos pequeños ensayos y trabajos periodísticos están recogidos en los volúmenes: D e música y músicos (1983) y el ya citado La música por dentro, ambos publicados por la Universidad $\mathrm{N}$ acional Autónoma de M éxico.

Un capítulo de gran aliento y de carácter cosmopolita en la trayectoria de Jorge Velazco - que, por lo demás, daría pie para especular sobre una eventual identificación del investigador con sus personajes- lo constituyen sus traducciones de los libros Ensayos ante una sonata, de Charles Ives (I975), un músico controvertido y con fama de ser uno de los compositores más solitarios de la 


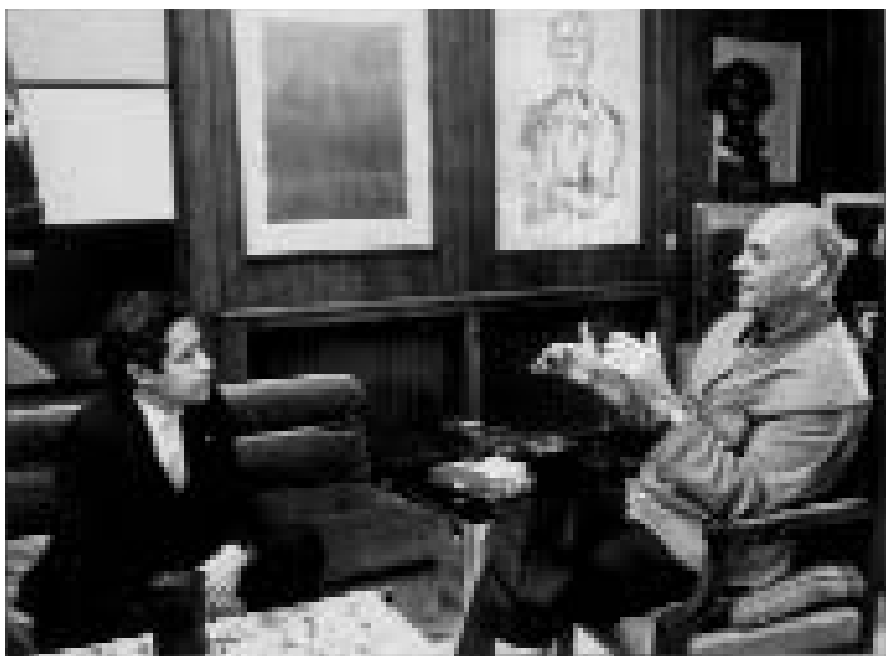

2. Jorge Velazco con Georg Solti, director de orquesta húngaro.

Reprografía: Gerardo Vázquez M iranda, Archivo Fotográfico IIE-UnAM.

historia, y la serie de ediciones en torno a Ferruccio Busoni que, en palabras del propio Velazco, es uno de los escasos músicos que suman una gran habilidad literaria y amplios conocimientos musicales a una profunda capacidad de reflexión estética. Las obras de estos pensadores musicales de nuestro siglo eran por completo desconocidas en español hasta que Jorge Velazco emprendiera sus traducciones. El primer libro de la serie, también publicado en 1975 , corresponde a una versión de la espléndida biografía de Busoni por el musicólogo británico Edward Joseph Dent. En fechas posteriores, Velazco vertió al español el volumen de su correspondencia y, directamente del alemán, su indispensable Pensami ento musical. H uelga recordar el impacto que significó la aparición de estos textos, nuevamente por cuenta de la U niversidad $\mathrm{N}$ acional Autónoma de M éxico, pues gracias a ellos muchos músicos y musicólogos pudimos acercarnos por primera vez a las ideas de este relevante filósofo y teórico musical.

Por último, me referiré al proyecto más ambicioso en la carrera de investigador de Jorge Velazco: el Diccionario de la música española e hispanoamericana, una magna apuesta editorial encabezada en M adrid por el doctor Emilio Casares Rodicio desde el Instituto Complutense de Ciencias M usicales, aus- 
piciada por el M inisterio de Cultura de España y la Sociedad de Autores y Editores de aquel país. Velazco fue, para M éxico, el director de este proyecto, al que dedicó cerca de trece años, de 1989 hasta 2002, fecha en que apareció el décimo y último volumen de la primera edición. No creo incurrir en exageración al señalar que a su profesionalismo y compromiso se debe en buena medida el éxito de la obra, si consideramos que, después de España, M éxico es uno de los países que cuentan con mayor número de entradas en el D iccionario. Por encima de los avatares editoriales y de sus virtudes 0 carencias, representa un invaluable avance en este campo porque es el primer trabajo enciclopédico sobre música mexicana que existe en el mundo.

Una parte del legado de Jorge Velazco en la que convergen las labores del director y del musicólogo son sus numerosos discos que han merecido una destacada difusión. Si tuviéramos que hablar de uno solo de ellos, mencionaríamos la primera grabación jamás realizada de la música de Antonio G omezanda, un compositor talentoso y sin embargo olvidado, cuya obra ahora conocemos gracias a esta producción. Pocos son los que recuerdan a Velazco como compositor y autor de un breve pero interesante catálogo de obras para diversas dotaciones: Willst du, para violín y piano, a partir de un texto anónimo alemán del siglo xviıI, Concierto para piano y orquesta, Concierto para piano y orquesta de cuerdas, Fantasía para guitarra y orquesta de cuerdas, Concierto para violín y orquesta, una sinfonía y una ópera inconclusa: Richelieu, son algunas de sus composiciones. Asimismo, poco se sabe de su efímero paso por el Conservatorio $\mathrm{N}$ acional como maestro de historia de la música y como investigador en el Centro $\mathrm{N}$ acional de Investigación, D ocumentación e Información M usical Carlos C hávez, mejor conocido como Cenidim, del Instituto $\mathrm{N}$ acional de Bellas Artes. A todos estos trabajos y desvelos, habría que sumar sus contribuciones a la hemerografía musical en publicaciones culturales de M éxico, España y Estados U nidos: Revista de Bellas Artes, Revista de la Universidad, Anales del Instituto de Investigaciones Estéticas, H eterofonía, Pauta, Cuadernos de M úsica I beroamericana, Latin America M usic Review... Gracias a sus fogueos en la administración, su currículum registra, en distintas fechas, los siguientes cargos: subjefe del $D$ epartamento de $M$ úsica del Instituto Nacional de Bellas Artes, director de Actividades Musicales de la unAm y subdirector general de D ifusión Cultural de la misma institución.

Su ritmo de trabajo era, en verdad, inaudito. Podía, al mismo tiempo, capitanear una orquesta y el festival que la acogía; actuar como principal director huésped de una agrupación sinfónica en Italia y continuar sus labores de 


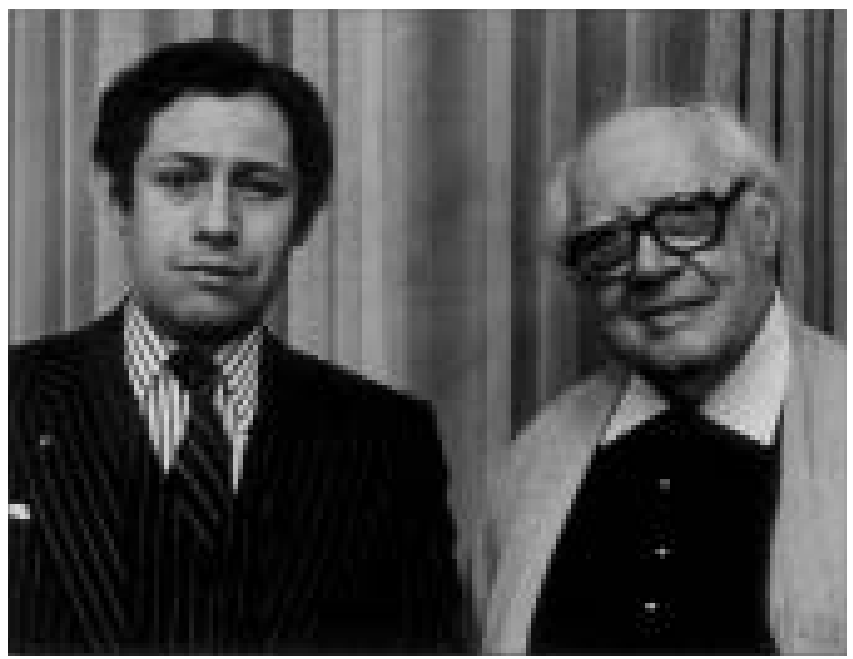

3. Jorge Velazco con Andrés Segovia, guitarrista español. Reprografía: Gerardo Vázquez M iranda, Archivo Fotográfico IIE-UnAM.

investigador; editar y redactar las voces para un diccionario enciclopédico y publicar artículos en el periódico o preparar las notas de los muchos conciertos que dirigía y, además, cuidar de tres hijos con un amor y una entrega ejemplares. Por desgracia o ironía del destino, sólo en la muerte encontró el descanso que él mismo se regateaba en vida.\$ 